\section{LA CONTRIBUCIÓN MILITAR A LA AYUDA HUMANITARIA: HACIA UN MODELO DE COOPERACIÓN}

\author{
José Javier Muñoz Castresana \\ Subdirector Gral. de Cooperación y Defensa Civil \\ de la Dirección General de Política de Defensa
}

\section{THE MILITARY CONTRIBUTION TO THE HUMANITARIAN HELP. TOWARDS A MODEL OF COOPERATION}

\begin{abstract}
When faced to situations of humanitarian crisis the Armed Forces are a notable added value in order to alleviate human suffering in a very quick and effective way. They have available personal and material means and the capacity to agilely and orderly deploy in situ, to quickly concentrate heavy means of transport and to carry out massive transporting. Because all these facts the Armed Forces are an especially suitable instrument in those situations.
\end{abstract}

KEY WORDS: Humanitarian help; peace missions; spanish laws; United Nations.

\section{LA PARTICIPACIÓN DE LAS FUERZAS ARMADAS EN MISIONES DE PAZ}

\section{INTRODUCCIÓN}

Es después de la Revolución Francesa cuando se forman los grandes Estados Nación en los que la primera idea que aporta cohesión a los ciudadanos, es la de la nación en armas como consecuencia de un planteamiento de defensa nacional y de la participación de cada uno de ellos en la protección de un territorio que consideran suyo y de unas estructuras económica y social también concebidas en términos nacionales.

Terminadas las dos Guerras Mundiales, este panorama empieza a cambiar y pronto encontramos en algunos países una concepción que va más allá de la pura Defensa $\mathrm{Na-}$ cional -ahora con mayúsculas-, para hablar de defensa aliada. Con el paso del tiempo nos encontramos también
RESUMEN: Ante situaciones de crisis humanitarias de gran magnitud, las Fuerzas Armadas pueden aportar un notable valor añadido para mitigar el sufrimiento humano de forma rápida y eficaz, pues disponen de unas características de orden personal y material, de una capacidad para desplegarse ágil y ordenadamente sobre el terreno, para concentrar medios pesados en poco tiempo y para realizar transportes masivos, que las convierten en un instrumento especialmente apto en estas situaciones.

PALABRAS CLAVE: Ayuda humanitaria; misiones de paz; normativa española; Naciones Unidas.

con que el despliegue territorial de los ejércitos, hasta esos momentos interno, ha pasado a obedecer a una concepción operativa e internacional.

En años más recientes, en las últimas décadas, numerosos condicionantes han producido un cambio del panorama estratégico. Se pueden citar los avances tecnológicos, las nuevas concepciones de las relaciones entre Estados, el nacimiento de nuevos sentimientos nacionales, la aparición del terrorismo internacional y la globalización como nuevos elementos configuradores de la realidad. Sin embargo, en un tiempo relativamente corto, hemos pasado de un mundo con una sola amenaza para el mundo occidental, conocida y prevista, a una nueva sensación de vulnerabilidad, a un escenario en el que las operaciones militares ya no son suficientes como solución única pero en el que la acción militar vuelve a cobrar un papel relevante.

Hoy no podemos hablar de un nuevo orden, libre de riesgos y amenazas a la estabilidad y a la paz internacionales. Los 
años noventa fueron testigos del estallido de numerosos conflictos, algunos de nuevo cuño, que han dividido a naciones enteras con enfrentamientos civiles, religiosos y étnicos. La amenaza del terrorismo ha pasado a primer plano y la lucha contra el mismo es considerada como un elemento clave de la estrategia de las organizaciones de seguridad y defensa.

Nos encontramos, en consecuencia, con un escenario estratégico distinto, marcado por los sucesos del 11 de septiembre de 2001 en Estados Unidos, los atentados del 11 de marzo de 2004 en Madrid y los del 7 de junio de 2005 en Londres. En este escenario, los medios militares tradicionales, con su organización y sus procedimientos de aplicación no son, por sí solos, un poder de disuasión suficiente ante este nuevo enemigo que no utiliza armas convencionales y para el que no existe un teatro de operaciones concreto.

Por otro lado, en la actualidad, proliferan los conflictos armados que, tanto por sus causas como por sus efectos, tienen implicaciones notables más allá del lugar en donde se producen. Hoy la seguridad es un reto, y lograr que sea efectiva requiere la concurrencia de la Defensa como uno de los medios necesarios para alcanzarla, junto al impulso de los derechos humanos, la lucha por la erradicación de la pobreza y la ayuda oficial al desarrollo, todos ellos elementos contribuyentes a esta seguridad.

Adicionalmente, hay que tener en cuenta que la seguridad y el equilibrio geoestratégico no siempre se apoyan en estados formalmente constituidos, o tienen su origen bien definido geográficamente. Los riesgos actuales son más sutiles, menos predecibles $y$, sobre todo, globales. $Y$ deben ser considerados mediante la acción coordinada de todas las capacidades de los estados. La acción militar debe representar el último recurso cuando ya han sido empleados, los esfuerzos diplomáticos, los policiales, los económicos, los sociales u otros, sin haber alcanzado éxito alguno.

Así, y en relación con las Fuerzas Armadas lo que se debate, no es sólo la idoneidad o la capacidad para enfrentarse a un enemigo asimétrico, sino la propia manera de concebir y ejecutar las operaciones militares para hacerle frente, especialmente en las ciudades, un escenario frecuente en las operaciones militares en curso en las que estamos involucrados los países desarrollados.
Pero independientemente del debate sobre cuáles son los conflictos en los que pueden, o no, ser utilizados los Ejércitos o sobre si su participación en operaciones de paz o misiones de ayuda humanitaria debe ser considerada como una nueva misión de las Fuerzas Armadas, la realidad nos presenta una sucesión de conflictos a los que la Comunidad Internacional se tiene que enfrentar para que nuestro mundo no se deteriore y sea posible la convivencia pacífica entre los pueblos.

En consecuencia, las Fuerzas Armadas de hoy en dia, se parecen poco a las de hace unos decenios. La mejora de sus capacidades, su utilización frecuente como una herramienta de los estados en su acción exterior y, en ocasiones, su empleo dentro de las propias fronteras en refuerzo o ayuda a otros organismos oficiales, han producido un cambio profundo en sus doctrinas, estructuras, medios y procedimientos de empleo y entrenamiento, propiciando una dinámica de adaptación permanente.

\section{La participación de las Fuerzas Armadas ESPAÑOLAS EN MISIONES DE PAZ}

Los ejércitos y la Armada españoles no han sido ajenos al cambio que se ha comentado. Es necesario pues, dibujar el escenario en el que se mueven nuestras Fuerzas Armadas cuáles son los nuevos requisitos para su empleo, sus necesidades actuales y -tomando como referencia los organismos internacionales de los que España es miembro- desarrollar cómo ha evolucionado su participación en las diferentes misiones de paz.

Hay que tener en cuenta que la aparición de una conciencia generalizada de solidaridad, junto con una mejor y más rápida información sobre todo lo que ocurre en el mundo, deberian ser factores de estabilidad y resolución pacífica de los conflictos. Pero lo cierto es que junto a estos nuevos fenómenos, ha surgido un gran número de tensiones derivadas del nacimiento de nuevos estados, reconstrucción de sociedades civiles, diferencias religiosas, étnicas, económicas, y un sinfín de nuevos retos, que es necesario afrontar para lograr la estabilidad.

Esta situación afecta a los Estados que buscan su pro-

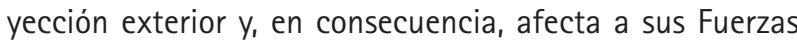
Armadas que han pasado de tener un papel meramente de- 
fensivo (territorial, de intereses o del ordenamiento constitucional) a uno activo, alli donde sea necesario defender o apoyar los intereses nacionales o los de la Comunidad Internacional.

Por otra parte, las alianzas y equilibrios entre los Estados buscan la ventaja de la seguridad y defensa compartidas, así como un papel más relevante en el concierto internacional, especialmente mediante la integración de sus Fuerzas Armadas en organizaciones militares internacionales. Unas Fuerzas Armadas que se han transformado en un factor muy importante de la política exterior de los países y que han debido cambiar sus organizaciones, medios, doctrinas y procedimientos para poder actuar allí donde los gobiernos consideran que están sus intereses nacionales, donde la Comunidad Internacional requiere actuaciones en defensa de la paz y la estabilidad mundiales, o en defensa de los Derechos Humanos y del Derecho Internacional. Por lo tanto, han de tener unas características esenciales tales como su rápida disponibilidad y una gran capacidad de proyección para, con ello, poder hacer frente a su empleo rápido y eficaz en los ámbitos interno e internacional.

Pero además de hablar de las características de esas fuerzas, es necesario describir cuál es "el escenario estratégico" si queremos analizar el cómo, para qué, cuándo y dónde, pueden ser empleadas. Esta descripción requeriría, por sí sola, un capítulo específico y un análisis comparado desde diferentes puntos de vista, que no son el objeto de estas reflexiones. Sin embargo, creo que es posible señalar algunos aspectos de ese escenario. Son los siguientes:

Aparición de nuevos riesgos y amenazas; nacimiento de una conciencia internacional sobre la necesidad de intervención en los conflictos, en defensa del Derecho Internacional Humanitario; asunción por parte de las Naciones Unidas de un papel relevante para el mantenimiento de la paz y la seguridad en el mundo, proporcionando la legalidad y legitimidad de las actuaciones, incrementando el número de sus operaciones', autorizando la ejecución de éstas en "conflictos internos" y justificando el uso de la fuerza militar; consolidación del liderazgo político y militar de los Estados Unidos de América; cambio en los conceptos estratégicos y de empleo de las organizaciones militares multinacionales de seguridad y defensa (OTAN, UE...), autorizando el empleo de fuerzas en operaciones fuera de su área de influencia, normalmente en apoyo de Naciones Unidas o de la Comunidad Internacional o como consecuencia de sus Resoluciones formales; utilización, por parte de los Estados, de sus Fuerzas Armadas como herramientas para defender sus intereses fuera de su territorio, o como muestra de sus compromisos en las organizaciones internacionales; uso de las Fuerzas Armadas como vehículos para mostrar la solidaridad y ayuda a paises que sufren cualquier tipo de desastre o situación de emergencia como consecuencia de catástrofes no producidas por conflictos armados.

Pero, una vez dibujado este panorama, cabe preguntarse qué deben hacer los componentes, militar o civil, que participan en las actuales misiones de apoyo a la paz. Entiendo, junto con otros observadores, que su trabajo debe circunscribirse a cuatro áreas de actuación básicas para que, desarrollando su actividad de forma coordinada, se lleven a cabo actividades relacionadas con:

- La Seguridad: habitualmente es aportada por las fuerzas militares y policiales desplegadas y cuyos objetivos fundamentales son la consecución de un entorno estable y el mantenimiento de la seguridad para que el resto de las actividades puedan desarrollarse.

- La Reconstrucción: a cargo de organizaciones nacionales o internacionales con capacidades económicas, mediante la creación de "grupos de donantes" que coordinan y canalizan los recursos monetarios en apoyo a una zona en conflicto y que tienen como objetivo la reconstrucción de las infraestructuras básicas imprescindibles y la rehabilitación del tejido económico.

- El Desarrollo político y democrático: normalmente a cargo de una o varias organizaciones internacionales (ONU, OSCE, EU...) y cuyo objetivo es la reestructuración, y en muchos casos la creación, de los tejidos políticos y sociales en la zona de conflicto de acuerdo con los estándares del Derecho Internacional y el tutelaje de su funcionamiento durante un período de tiempo, para permitir a estos países reintegrarse a la "comunidad internacional" con todas las garantías.

- La Asistencia Humanitaria: desarrollada por las "agencias" de Naciones Unidas o internacionales y por un amplio abanico de organizaciones gubernamentales $y$ no gubernamentales, que tienen como objetivo el apoyo directo a la población en la zona de conflicto, no sólo en el campo del suministro alimentario, sino también en el 
desarrollo de la educación, o el fomento de medidas de protección de las minorías.

A la vista de lo dicho, es claro que para planear y ejecutar las operaciones de una misión de paz, se deben tener en cuenta no sólo las necesidades y posibilidades militares, sino también las policiales, las políticas, las financieras y las sociales. En consecuencia, la decisión del envío de fuerzas militares a una misión por parte de un gobierno, tiene como resultado inmediato la participación de diversos organismos del Estado, ya que en ella se ven implicados las fuerzas militares, los estamentos políticos, las instituciones y organismos de cooperación y las organizaciones no gubernamentales de asistencia humanitaria que actúan en el país.

\section{LA NORMATIVA ESPAÑOLA}

Antes de seguir adelante, deberiamos recordar la importancia de los documentos básicos que regulan la Defensa en España. En primer lugar, y una vez dado por conocido el artículo 8 de la Constitución, sería conveniente recoger lo que dice la Directiva de Defensa Nacional, en vigor en el momento de redactar estas líneas, y citar algunos de sus párrafos. Este documento, sin clasificación restrictiva de seguridad, nos da una idea de cuáles son los planteamientos de nuestro Gobierno en lo que se refiere a la actuación de nuestras Fuerzas Armadas. Este documento, sancionado por el Presidente de Gobierno dice, entre otras cosas, lo siguiente:

- En cuestiones de seguridad y defensa, Europa es nuestra área de interés prioritario; somos Europa y nuestra seguridad está indisolublemente unida a la del continente.

- España promoverá e impulsará una auténtica política europea de seguridad y defensa, respaldará las iniciativas tendentes a alcanzar una defensa común, contribuirá a que la Unión Europea se dote de las capacidades civiles y militares necesarias para poder intervenir activa y autónomamente en la prevención y resolución de conflictos, y en la preservación de la paz y la seguridad internacionales de acuerdo con la Carta de las Naciones Unidas.

- Para ello, deberemos estar en condiciones de poder participar con determinados países, si así se decidiese, para el desarrollo de capacidades militares más exigentes y en la adquisición de compromisos más vinculantes, en los términos previstos en el Tratado Constitucional de la Unión Europea.

- Esta prioridad es compatible con una relación transatlántica robusta y equilibrada, un elemento también esencial de la defensa europea, como prevé el propio Tratado Constitucional. Los aliados de ambos lados del Atlántico compartimos y defendemos los mismos principios y valores. España tiene el convencimiento de que una Europa fuerte no debilita dicha relación sino que, por el contrario, la refuerza. En este sentido, España es un aliado firme y claramente comprometido con la Alianza Atlántica, y que además mantiene una relación estrecha y consolidada con los Estados Unidos; una relación que debe estar articulada sobre la lealtad, el diálogo, la confianza y el respeto recíprocos.

- Asimismo, el área del Mediterráneo es de un interés especial para España. En materia de seguridad y defensa, las iniciativas que agilicen el diálogo e impulsen la cooperación bilateral con los países de la región son indispensables. También apoyaremos las iniciativas multilaterales de la Unión Europea, de la Alianza Atlántica y de la Organización para la Seguridad y Cooperación en Europa dirigidas a la región mediterránea.

- Iberoamérica constituye otra área preferente para España. La política de defensa intensificará las relaciones bilaterales y, en su caso, de cooperación militar. Igualmente, apoyaremos las iniciativas regionales encaminadas a reforzar la cooperación multilateral entre los países de la Comunidad Iberoamericana.

Hasta noviembre del año 2005, las misiones militares en el exterior eran decididas y ejecutadas según un marco político basado principalmente en acuerdos de Consejo de Ministros, comparecencias parlamentarias, declaraciones políticas y lo establecido en las sucesivas Directivas de Defensa Nacional. Sin embargo, la Directiva de Defensa Nacional en vigor, señala que la actuación de las Fuerzas Armadas españolas se enmarcará dentro de un multilateralismo eficaz, que requerirá el cumplimiento de dos condiciones: en primer lugar, que exista una decisión previa de Naciones Unidas o, en su caso, otra organización multinacional de la que España forme parte y, en segundo lugar, que se acuerde con la participación activa del Parlamento.

La Directiva, que define los escenarios y prioridades para la Política de Defensa española, establece como una de 
las directrices para su desarrollo, la elaboración de una nueva Ley Orgánica de la Defensa Nacional en la que se incluirán las misiones y cometidos de las tuerzas amadas, se establecerán las bases de la organización militar, se definirán los principios esenciales que deben inspirar su empleo y se determinará la forma en que el Parlamento debe pronunciarse sobre la participación en operaciones militares en el exterior. Pero si importante es la Directiva, aún mayor es la trascendencia de la Ley Orgánica de la Defensa Nacional.

Esta ley nos explica cuál es la finalidad de la Política de Defensa, y es de esa explicación de la que podemos extraer el objetivo de las Fuerzas Armadas en la realización de misiones de paz. La Ley dice que la Política de Defensa tiene por finalidad la protección del conjunto de la sociedad española, de su Constitución, de los valores superiores, principios e instituciones que en ésta se consagran, del Estado social y democrático de derecho, del pleno ejercicio de los derechos y libertades, y de la garantía, independencia e integridad territorial de España. Asimismo, tiene por objetivo contribuir a la preservación de la paz y seguridad internacionales, en el marco de los compromisos contraídos por el Reino de España.

Y es precisamente dentro de ese objetivo de contribuir a la preservación de la paz y seguridad internacionales donde se enmarca el compromiso de participar en misiones de paz, en la medida que así sea decidido por el Gobierno y aprobado por el Parlamento. La Ley Orgánica 5/2005 de la Defensa Nacional, promulgada el 17 de noviembre de 2005, regula suficientemente, desde un punto de vista legal, la participación de unidades militares en operaciones fuera de nuestro territorio nacional, permite la contribución del mundo militar a la Ayuda Humanitaria y se adapta a los cambios y nuevos requisitos a los que hacía mención más arriba. Comentemos brevemente algunos de los aspectos más novedosos en relación con la anterior, la L0 6/1980, modificada por la 1/1984.

Ya desde el principio y en su exposición de motivos, dibuja la nueva Ley, el cambio de escenario estratégico y destaca la necesidad de regular una realidad, la participación de las Fuerzas Armadas en el campo internacional. Más adelante indica claramente -como se ha mencionado-, que una de las finalidades de la Política de Defensa es la contribución a la preservación de la paz y seguridad internacionales, en el marco de los compromisos contraídos por el Reino de España, lo que no deja margen para la duda sobre la legalidad de las operaciones militares españolas fuera del territorio nacional.

Además, la Ley explica que, a la vista de la experiencia adquirida, la organización básica de las Fuerzas Armadas debe basarse en dos estructuras: una orgánica y otra operativa. Al mismo tiempo, describe claramente cuáles son las Misiones de las Fuerzas Armadas, las circunscribe a dos ámbitos, interno y externo, y señala los tipos de operaciones que pueden ser realizadas. Pero la novedad más importante en relación con esta legalidad, reside en el papel que asigna al Parlamento en relación con el envío de unidades militares, al decir que en particular, al Congreso de los Diputados le corresponde autorizar, con carácter previo, la participación de las Fuerzas Armadas en misiones fuera del territorio nacional y asigna al Gobierno el acordar la participación de las Fuerzas Armadas en misiones fuera del territorio nacional.

Quisiera también resaltar que la Ley impone una serie de condiciones para que se puedan llevar a cabo las misiones en el exterior. Estas condiciones son los cimientos sobre los que edificar el razonamiento para la participación en cada caso. Son las siguientes:

- Que se realicen a petición expresa del Gobierno del Estado en cuyo territorio se desarrollen, sean autorizadas en Resoluciones del Consejo de Seguridad de Naciones Unidas o acordadas por organizaciones internacionales de las que España forme parte.

- Que cumplan con fines defensivos, humanitarios, de estabilización o de mantenimiento y preservación de la paz.

- Que sean conformes con la Carta de las Naciones Unidas y que no contradigan o vulneren los principios del Derecho Internacional.

En definitiva, se puede decir que la Ley supone un marco regulador suficiente; que es un norma nacional que cumple escrupulosamente con el Derecho Internacional, como no podía ser de otra forma; que permite la contribución de las Fuerzas Armadas a la Ayuda Humanitaria; y que legitima nuestra participación formando parte de coaliciones u organizaciones internacionales.

Hay que comentar, por último, que como desarrollo de la Directiva y de la Ley, existe una importante normativa que, 
siendo de segundo nivel, sirve para dar forma a las respuestas de los interrogantes que plantea cualquier misión de paz en el exterior. No obstante, no se pretende con estas líneas, llevar a cabo un estudio de carácter únicamente legal, por lo que salvo lo que se indica más arriba no desarrollaré más este aspecto.

\section{LA SITUACIÓN ACTUAL}

En un mundo interdependiente como es el actual, nos encontramos con que la estructuración de las relaciones internacionales en base a equilibrios estratégicos, la integración de los países en organismos multinacionales, la relación política económica y social de los Estados, la existencia de mecanismos internacionales para actuar sobre las áreas de conflicto y la presión de las opiniones públicas para actuar en ayuda de los pueblos que sufren conflictos, han hecho que los escenarios probables de empleo del poder militar se circunscriban, mayoritariamente, a la ejecución de operaciones de apoyo a la paz y misiones de ayuda humanitaria, ambas claramente especificadas para nuestras Fuerzas Armadas en el Título III de la Ley. Estas operaciones, que nacieron con la creación de Naciones Unidas como organización responsable de la paz y la estabilidad en el mundo, han ido evolucionando con el paso del tiempo y hoy son operaciones distintas a aquellas en las que el objetivo era simplemente el cese del conflicto armado y por lo tanto únicamente eran empleadas las fuerzas militares para lograrlo. Las operaciones exceden en la actualidad el campo militar y necesitan la confluencia de varios componentes (de seguridad, de reconstrucción, de control político y democrático y de asistencia humanitaria).

La experiencia acumulada por nuestro país con la participación en casi 60 operaciones diferentes de unos 100.000 militares, supone un amplio bagaje de conocimientos, lecciones aprendidas, experiencias y adaptaciones que la organización militar ha tenido que llevar a cabo. Sabemos bien que la mayoría de las guerras de hoy en día, no se producen entre Estados, sino dentro de los Estados y esta situación marca la fisonomía de las operaciones en las que el objetivo final no es sólo terminar con la situación de enfrentamiento armado, sino también crear las condiciones para el restablecimiento de las instituciones básicas, tutelar el desarrollo de los Estados de acuerdo con las normas del
Derecho Internacional y del Derecho Humanitario, apoyar el desarrollo sostenible de un tejido económico mínimo y prestar ayuda humanitaria a las poblaciones que sufren las consecuencias de la guerra. Estos condicionantes obligan a una organización, unos objetivos y unos procedimientos que hacen las actuales operaciones de paz más complejas y exigentes no sólo para cada país individualmente, sino también para la "comunidad internacional", la cual debe empeñarse con fuerzas militares y policiales pero también con contingentes civiles y recursos financieros.

Derivado de todo ello, y teniendo en cuenta esa experiencia, al hablar de misiones de paz, podemos considerar tres componentes básicos: el de seguridad, el civil y el meramente administrativo (dedicado al sostenimiento de la operación). En los primeros momentos de una operación, cuando los enfrentamientos armados están todavía presentes, adquiere la mayor importancia el componente de seguridad (militar) cuyos objetivos básicos son conseguir el cese de las acciones armadas en la zona, proporcionar seguridad (a la población y a las agencias de asistencia) y apoyar las acciones de asistencia humanitaria y de desarme. En esta fase, el contingente civil, en el que en algunos casos se incluye el policial, evalúa las necesidades para el desarrollo de las instituciones, los diferentes procedimientos de transición a la democracia, marca las pautas a seguir para la reconstrucción de los tejidos político, económico y social y establece los mecanismos de ayuda tanto a la población como al país.

Conforme la situación evoluciona, el componente militar disminuye sus capacidades de combate y aumenta las de apoyo al civil y las de asistencia. Por su parte, el componente civil adquiere un mayor protagonismo y desarrolla las acciones dirigidas a la reconstrucción, el apoyo a las estructuras política y social y la ayuda humanitaria.

\section{El papel básico de Naciones Unidas. REQUISITOS Y CONDICIONANTES PARA UNA INTERVENCIÓN}

Las Naciones Unidas, en la Carta firmada en San Francisco el 26 de junio 1945, instan a los países miembros a mantener la paz y la seguridad internacionales y con tal fin tomar medidas colectivas eficaces para prevenir y 
eliminar amenazas a la paz; y lograr por medios pacíficos, y de conformidad con los principios de la justicia y del derecho internacional, el ajuste o arreglo de controversias o situaciones internacionales susceptibles de conducir a quebrantamientos de la paz. Pero es evidente que, cuando el arreglo pacífico de controversias no es posible, la ONU necesita de algún elemento para hacer cumplir sus Resoluciones.

Es por ello que, más allá del Capítulo VI de la Carta, se hizo necesario considerar un Capítulo VII en el que se dice que cuando el Consejo de Seguridad estimare que las medidas de que trata el artículo 41 (que no implican el uso de la fuerza) pueden ser inadecuadas o han demostrado serlo, podrá ejercer, por medio de fuerzas aéreas, navales o terrestres, la acción que sea necesaria para mantener o restablecer la paz y la seguridad internacionales. Tal acción podrá comprender demostraciones, bloqueos y otras operaciones ejecutadas por fuerzas aéreas, navales o terrestres de miembros de las Naciones Unidas. Y ello nos da la necesaria legitimidad internacional para prepararnos y para llevar a cabo misiones, no sólo de defensa del propio territorio, sino también de actuación de acuerdo con la Carta de ONU y con sus correspondientes Resoluciones. Se deduce, pues, la necesidad de considerar si es necesario exigir algunos requisitos a las Fuerzas Armadas de aquellos países que, con arreglo a las normas habituales de conducta internacional y de compromiso con la legalidad, tratan de intervenir para lograr la paz entre los pueblos.

Para poder llevar a cabo operaciones de paz de acuerdo con la Carta, con nuestro ordenamiento jurídico, con nuestros compromisos internacionales contraídos y con lo que demanda nuestra propia opinión pública, ha habido que afrontar cambios considerables en la organización, los medios, la preparación y los procedimientos de empleo de nuestras Fuerzas Armadas. Pero ha sido la práctica diaria de nuestra participación en misiones en el exterior -ya desde hace muchos años-, la que nos ha llevado a realizar los cambios de detalle necesarios. Entre ellos se pueden destacar, en líneas generales, los siguientes:

- Las unidades militares que participan en las misiones, no son hoy orgánicas, sino diseñadas, caso por caso, para cada una de las misiones.

- Muy frecuentemente, se utilizan elementos y unidades de más de un ejército y de más de un país, lo que com- plica el planeamiento, el seguimiento y el control de las operaciones.

- En consecuencia, las capacidades de mando y control y comunicaciones han sido potenciadas, dotando a las unidades de medios de enlace e información táctica y por satélite.

- Las actividades de las fuerzas militares y de las organizaciones de asistencia que actúan en las zonas de despliegue, deben ser coordinadas. Esto obliga a disponer de secciones de unidades militares de cooperación cívicomilitar que sean capaces de coordinar las actividades de todos los actores en un operación.

Estos requisitos, junto con condicionantes políticos, sociales y financieros, han sido tenidos en cuenta para adaptar las Fuerzas Armadas a las necesidades actuales, de forma que las unidades militares puedan actuar sin limitaciones operativas. No obstante, cada nación y cada organización multinacional tienen sus propios órganos de decisión, procedimientos y normas y todas ellas se articulan en torno a documentos de carácter legal donde se determinan las obligaciones y derechos de cada una de las partes. Sin embargo podemos constatar que se han desarrollado diferentes modalidades de empleo de los ejércitos, que van desde la ayuda humanitaria hasta la imposición de la paz, y cuyos condicionantes generales son:

Necesidad de un Mandato de las Naciones Unidas (mediante Resoluciones de su Consejo de Seguridad) que establezcan, apoyen o autoricen el empleo de la Fuerza ante situaciones de violaciones, sistemáticas y graves, de los Derechos Humanos; Respeto al Derecho Internacional Humanitario y al Derecho Internacional; Despliegue y uso de la Fuerza de acuerdo con unos procedimientos establecidos y comúnmente aceptados; Necesidad de firma, ratificación y puesta en vigor de acuerdos y herramientas como los Estatutos de Fuerzas (SOFA) y las Reglas de Enfrentamiento (ROE's).

Pero además de los requisitos y condicionantes generales citados, las propias necesidades de las unidades militares establecen una serie de requisitos y condicionantes adicionales:

- Decisión de empleo: Es siempre política y debe incluir, al menos, la justificación de su utilización, la entidad de las fuerzas, el plazo de actuación y los procedimientos de financiación. 
- Marco legal específico para la misión: Una vez tomada la decisión de participar, es necesario redactar y firmar una serie de documentos que, tomados en su conjunto, proporcionan el marco legal y de actuación de las Fuerzas Armadas en una operación. Entre ellos, a nivel militar, son de destacar:

- Los Términos de Referencia (TOR) donde se determinan las condiciones generales de la participación de las Fuerzas Armadas en cada estructura.

- El Estatuto de Fuerza (SOFA) o de misión (SOMA), donde se pormenorizan los derechos y deberes de los militares que actúan en otro país.

- Las Reglas de Enfrentamiento (ROE's) donde se detallan las autorizaciones o prohibiciones que deben aplicar las unidades militares en cada momento de acuerdo con el desarrollo de las operaciones y la situación en la zona.

- Acuerdos Técnicos (AT's) y Procedimientos Normalizados (SOP's), en los que se detallan las cuestiones administrativa y operativas de las fuerzas asignadas, del personal nacional y de los países en los que ejecutan operaciones.

Ahora bien, hasta este momento hemos hablado principalmente de intervenciones de un país y nos hemos referido específicamente al nuestro. Sin embargo, son frecuentes aquellos casos en los que las Fuerzas Armadas ejecutan misiones dentro de "coaliciones internacionales" configuradas para situaciones concretas (Guerra del Golfo, Libertad Duradera, Libertad Iraquí...).

En estos casos, además de los anteriores documentos, se redactan y firman Memorandos de Entendimiento con todos los países participantes y con todos aquellos en los que se van a desarrollar las operaciones, ya sean tácticas o de apoyo, completándose así el marco legal para la operación.

\section{SínTESIS FinAL}

Dejando al margen el debate sobre cuáles son los conflictos en los que pueden, o no, ser utilizados los Ejércitos 0 sobre si su participación en operaciones de paz o misiones de ayuda humanitaria deben ser consideradas como nuevas misiones de las Fuerzas Armadas, la realidad nos presenta una sucesión de crisis a las que nuestro país y la Comunidad Internacional se tienen que enfrentar. Sin embargo, aunque las misiones de paz no son suficientes como solución única, la acción militar vuelve a cobrar un papel creciente.

Son muy diversos los factores que han producido, en los últimos años, un cambio del panorama estratégico. En un tiempo relativamente corto -si tratamos de tener una visión histórica-, se ha pasado de un mundo con una sola amenaza, conocida y prevista, a una nueva sensación de vulnerabilidad, a un escenario en el que los riesgos son más numerosos, menos predecibles y muchas veces globales.

Esto, junto con la conciencia internacional de intervenir por cuestiones humanitarias o por acciones en contra del Derecho Internacional, ha producido un incremento sustancial de la intervención de las Fuerzas Armadas de los países desarrollados, como elementos de la acción exterior de los Estados. Todo ello ha producido un cambio profundo en las doctrinas, estructuras, medios y procedimientos de entrenamiento y empleo, propiciando una dinámica de adaptación permanente a las circunstancias de cada momento. $Y$ los ejércitos y la Armada españoles no han sido ajenos a este cambio. Nuestras Fuerzas Armadas han pasado, de tener un papel meramente defensivo (territorial, de intereses o del ordenamiento constitucional) a uno activo, allí donde sea necesario defender o apoyar los intereses nacionales o los de la Comunidad Internacional. Pero su empleo en el exterior está condicionado por lo establecido en las regulaciones internacionales, en las nacionales y en unos principios que limitan las capacidades a utilizar y los procedimientos de actuación en las operaciones.

Sin embargo, no debemos olvidar que una conciencia de solidaridad, junto con una mejor y más rápida información sobre todo lo que acontece en el mundo, deben ser los principales factores de estabilidad y resolución pacífica de los conflictos. 


\section{LA CONTRIBUCIÓN MILITAR A LA AYUDA HUMANITARIA: HACIA UN MODELO DE COOPERACIÓN}

\section{LA AYUDA HUMANITARIA, UNA NECESIDAD}

A lo largo de la historia se han producido acontecimientos naturales con efectos de destrucción de la vida humana, de la vida natural, de las infraestructuras, de las condiciones de vida, de pérdida de patrimonio (obras de arte, efectos documentales, bellezas naturales...). Estos hechos originan víctimas, daños y desplazamientos de grandes masas de población, y siempre o casi siempre, con una desorganización de la vida social y de la conducta humana que hace aconsejable la declaración legal de la emergencia. Existen, por otro lado, otro tipo de desastres, los originados por la conducta del Hombre, por una conducta que prima los intereses del "yo" o del "nosotros", sobre los intereses de la mayoría. Muchas veces las consecuencias de uno y otro tipo de desastres son similares y es necesaria la intervención de un elemento superior que contribuya a paliar el sufrimiento y la desgracia. En numerosas ocasiones, ese elemento es la "Ayuda Humanitaria".

Podemos decir que todos, en mayor o menor medida, hacemos ayuda humanitaria. El joven que cuida del anciano, el rico que socorre al pobre, el culto que instruye al lego... Todo aquello que sirva para proporcionar desinteresadamente una mejora en las condiciones básicas de vida de un ser humano, es de alguna forma ayuda humanitaria.

Pero, evidentemente, no es este aspecto tan individual el que veremos en este trabajo. Cuando hablamos de ayuda humanitaria hoy en dia, nos imaginamos una actividad más organizada que el trabajo, muchas veces callado y casi aislado, del voluntario o el misionero que ofrecen su solidaridad y su caridad a los más necesitados, lejos de su tierra, su familia y sus amigos. Cuando hablamos de ayuda humanitaria, se nos va la mente a grandes organizaciones, gubernamentales o no, con capacidad de llevar adelante proyectos que mitiguen el sufrimiento lejos del territorio nacional.

No es objeto de este trabajo entrar en distinciones entre la ayuda humanitaria y la asistencia humanitaria, cuyo concepto se considera tradicionalmente conformado en el Marco del Derecho Internacional Humanitario, principalmente del Derecho de Ginebra. Tampoco se pretende comentar la idea de la injerencia humanitaria, más propia de debate en el seno de las Naciones Unidas y teniendo en la mano su Carta fundacional. Si se pretende en cambio hablar del cómo y el porqué de la contribución militar a la primera de ellas.

Ante situaciones de crisis humanitarias de gran magnitud, las Fuerzas Armadas pueden aportar un notable valor añadido para mitigar el sufrimiento humano de forma rápida y eficaz, pues disponen de una serie de características de orden personal y material, de una capacidad para desplegarse ágil y ordenadamente sobre el terreno para concentrar medios pesados en poco tiempo y para realizar transportes masivos, que les convierte en un instrumento especialmente apto en estas situaciones.

Las operaciones militares de ayuda humanitaria de emergencia son un componente más de la acción exterior del Estado, que se emprenden normalmente para satisfacer peticiones expresas de los países asolados por catástrofes; cuando no existen medios alternativos a los militares, o éstos se consideran más adecuados.

Su objetivo principal es mitigar el sufrimiento humano y se realizan siempre, incluso en situaciones de conflicto, atendiendo a los principios de humanidad, imparcialidad y neutralidad establecidos por la resolución 462/1182 de la Asamblea General de Naciones Unidas y contemplados tanto en las Directrices de Oslo como en las Directrices sobre el uso de medios militares y de defensa civil en emergencias complejas (MODA 2003).

\section{LAS NUEVAS MISIONES MILITARES}

En la actualidad proliferan los conflictos armados que, tanto por sus causas como por sus efectos, tienen implicaciones notables en la paz y en el bienestar de los ciudadanos. Hoy, la seguridad es un reto complejo, cuya conquista requiere la concurrencia de muchos actores, y entre ellos la Defensa y la Ayuda Oficial al Desarrollo, cuya coordinación y colaboración debe estar enfocada a crear un círculo virtuoso que contribuya eficazmente a extender la paz y el progreso, mucho más allá de nuestras fronteras. 
Pero esta coordinación entre Defensa y Ayuda Oficial al Desarrollo debe ir construyéndose poco a poco con el transcurso del tiempo. Debemos de ir acomodándonos los unos a los otros. No es un proceso que se pueda dar por concluido de un día para otro. Debemos ir encontrando nuevos espacios de colaboración que beneficien y refuercen ese círculo virtuoso en aras de la seguridad y la paz internacionales.

Si repasamos los contenidos de distintos estudios militares, notaremos que con frecuencia se hace referencia a "las nuevas misiones". Y esto es así desde hace años. El concepto de nuevas misiones ha sido en ocasiones ambiguo aunque para algunos, el elemento diferencial de las mismas reside en la idea de que se trata de misiones relacionadas con lo que se ha venido a considerar de forma más concreta, como misiones de ayuda humanitaria. Lo cierto es que hoy la Ley Orgánica de la Defensa Nacional, da legitimidad a la contribución militar a la ayuda humanitaria.

Es verdad que dentro de esa ambigua denominación de nuevas misiones entra todo un complejo y diverso escenario de acciones, que abarca desde actuaciones especificas de uso de la fuerza, hasta funciones de ayuda sanitaria o de rescate, aprovisionamiento, transporte y apoyo a refugiados, construcción de centros de asistencia, distribución de productos de diversa índole, etc. Es, por tanto, en esta complejidad en la que encontramos el problema de definir de manera clara e inequívoca unas delimitaciones que las encuadren y circunscriban para determinar los modos correctos de actuación. Tal vez nos ayuden a comprender mejor esa complejidad, las palabras publicadas de Tomás Torres, abogado, economista y comandante del Ejército de Tierra, al volver de su misión en Afganistán:

\footnotetext{
"Recientemente he estado en Afganistán y he comprobado sobre el terreno una situación que no sabría decir si es de posguerra, de preguerra, o quizá y a lo peor, de entreguerras. En el norte, especialmente en Kabul, hay una tensa calma, compatible con unas indisimuladas ansias de vivir en paz después de más de treinta años de continuas guerras.

Kabul, con más de dos millones y medio de habitantes, carece de alcantarillado; la red de energía eléctrica es muy insuficiente y su suministro, con temperaturas en invierno de hasta menos veinte grados, en absoluto está garantizado, no hay agua potable, ni telefonía fija, la comunicación es por teléfono móvil vía satélite, las carreteras suelen ser
}

caminos impracticables, la seguridad social no existe, los hospitales y la sanidad no merecen tal nombre, el Estado es sumamente débil, la policía no puede garantizar la seguridad, los tribunales casi no ejercen jurisdicción, la infancia no está escolarizada, los derechos humanos desconocidos, la actividad económica es de mera subsistencia, opio aparte, y si algo funciona, a pesar de los esfuerzos del presidente Karzai, es gracias al despliegue de las fuerzas de ISAF, cuya presencia es fundamentalmente disuasoria.

A lo anterior hay que sumar la situación de la mitad de la población, la femenina, que carece de los más elementales derechos. Aún hoy los matrimonios de las afganas frecuentemente son concertados por sus padres; durante años se les ha prohibido estudiar, trabajar, e incluso salir solas a la calle; el burka, aunque ya no es obligatorio, se ha impuesto de manera que ha convertido a la mujer afgana en un fantasma viviente; las viudas, que después 30 años de guerra son muchas, se ven avocadas a la prostitución o, peor aún, al suicidio, porque carecen de medios de subsistencia".

Ante palabras como éstas, el lector probablemente se preguntará si sería honesto permanecer impasibles. Creo que la respuesta es un no rotundo.

La acción exterior española para la resolución de conflictos se basa en el respeto escrupuloso de la legalidad internacional y en el reconocimiento de las Naciones Unidas como organización responsable de velar por la paz y la seguridad internacional y hoy, los militares podemos decir con orgullo, que ningún miembro de nuestras Fuerzas Armadas ha sido inculpado, por un tribunal internacional, por acciones ilegales o deshonrosas en el desarrollo de una misión en el exterior. Por otra parte, la acción exterior española asume el cumplimiento de los compromisos que hemos contraido con las organizaciones internacionales a las que pertenecemos, como la ONU, la Unión Europea, la Alianza Atlántica y la Organización para la Seguridad y Cooperación en Europa con objeto de contribuir a extender la paz, la seguridad y la estabilidad en el mundo.

La actuación de nuestras Fuerzas Armadas en el exterior requiere, pues, el cumplimiento de unas condiciones, de acuerdo con la Ley Orgánica 5/2005 de la Defensa Nacional, promulgada el 17 de noviembre de 2005. Entre esas condiciones, que dan legitimidad a nuestras actuaciones fuera de territorio nacional quisiera destacar las que se refieren al hecho de que se realicen por petición expresa 
del gobierno del Estado afectado o que estén autorizadas por Resoluciones del Consejo de Seguridad de las Naciones Unidas; que cumplan con los fines defensivos, humanitarios, de estabilización o de mantenimiento y preservación de la paz; que sean conformes con la Carta de las Naciones Unidas y que no contradigan o vulneren los principios del derecho internacional convencional; y por último, que el Gobierno haya realizado una consulta previa y recabado la autorización del Congreso de los Diputados. La Ley Orgánica de la Defensa Nacional regula suficientemente, desde un punto de vista legal, la participación de unidades militares en operaciones fuera de nuestro territorio nacional y permite la contribución del mundo militar a la Ayuda Humanitaria. Este planteamiento de "contribuyentes" a la Ayuda Humanitaria es reconocido y valorado por casi todos los sectores de la sociedad.

En este sentido, quisiera traer a estas páginas el comentario del Presidente de Cruz Roja Española, cuando, en el Fórum Europa, a principios del año 2007, decía:

"La humanitaria es una de las respuestas que debe dar la comunidad internacional a las crisis, pero no debe ni puede ser la única. Las crisis, como hemos visto, tienen profundas raíces políticas, económicas, históricas y éstas deben ser abordadas por la comunidad internacional. Pero debemos también ser realistas respecto a nuestras limitaciones: la respuesta humanitaria es, en este sentido, insuficiente. Por ello, debe complementarse con otras actuaciones de la comunidad internacional".

\section{LAS OPERACIONES}

Nuestras Fuerzas Armadas vienen actuando fuera de nuestras fronteras en todo tipo de operaciones de paz, de ayuda humanitaria y en misiones de observadores. Estas operaciones adquirieron desde finales de los años ochenta, una importancia creciente como catalizadores de estabilidad y como una forma de mostrar la solidaridad española ante el sufrimiento humano y en apoyo a otros pueblos. De este modo, los militares españoles han acumulado una valiosa experiencia en el campo de la paz y en el de la resolución de conflictos. Podemos decir que nuestras Fuerzas Armadas son un elemento relevante de la acción exterior española en materia de Construcción de la Paz.
Ya en el año 1971, A. D. Biderman argumentaba ("Towards Redefining the Milirary") a favor de que se reconociese a las fuerzas uniformadas el carácter de una organización de emergencia, para hacer frente, tanto a las amenazas del exterior como a desastres y misiones rutinarias de gran envergadura, cuestiones que figuran en todos los planes de actuación de las Fuerzas Armadas de los países desarrollados.

En este sentido, las operaciones de ayuda humanitaria de emergencia de nuestras Fuerzas Armadas, son decididas por el Gobierno para atender a peticiones concretas de ayuda de los países afectados por las diferentes catástrofes, realizadas bilateralmente 0 a través de organizaciones internacionales. En las solicitudes de ayuda, normalmente se definen las necesidades y se concretan las capacidades requeridas para paliar los efectos de las catástrofes y mitigar el sufrimiento de la población directamente afectada.

El ofrecimiento de un contingente militar para responder a las peticiones, se lleva a cabo tras el correspondiente proceso de la decisión en el que, de forma coordinada entre los ministerios implicados, se evalúan los factores que en mayor o menor medida pudieran afectar al desarrollo de la operación, entre ellos la posibilidad de que las capacidades requeridas puedan ser o no aportadas, en tiempo y lugar, por el estamento civil y, cómo no, la necesidad de evitar la injerencia en eventuales conflictos internos del país afectado.

Por ello, el envío de contingentes militares con fines humanitarios ha sido siempre muy bien aceptado y acogido por los países solicitantes, los cuales han prestado normalmente la máxima colaboración para su rápido despliegue y asentamiento, y han dado facilidades para que éstos puedan desarrollar su misión.

La eficacia de nuestros contingentes militares en las operaciones de ayuda humanitaria de emergencia ha sido considerada hasta el momento muy satisfactoria, y así lo han reconocido tanto las autoridades de los países asolados, como las poblaciones directamente beneficiadas, lo cual constituye el mejor indicador del interés de estas operaciones.

Nuestras Fuerzas Armadas han participado en las siguientes operaciones militares de ayuda humanitaria de emergencia, en los últimos 10 años: 
- 1998. Operación Alfa-Charlie para paliar los efectos del huracán "Mitch", en Centroamérica.

- 1999. Operación Alfa-Romeo para apoyo a los refugiados albano-kosovares ante al éxodo masivo generado por el conflicto interétnico entre las poblaciones serbia y albanesa.

- 2000. Operación India-Mike para ayudar durante las graves inundaciones sufridas en Mozambique.

- 2005. Operación Respuesta Solidaria I para mitigar los efectos del tsunami del océano Índico.

- 2005. Operación Respuesta Solidaria II para paliar las consecuencias del terremoto ocurrido en Pakistán.

- Además de estas operaciones, se han realizado innumerables colaboraciones con la Agencia Española de Cooperación Internacional para el Desarrollo y otras instituciones, para facilitar el envío de ayuda humanitaria de emergencia.

En sintesis, se pude decir que nuestras Fuerzas Armadas desplegadas en el exterior han estado y están abiertas a colaborar con las organizaciones e instituciones con responsabilidad en la prestación de ayuda humanitaria, y así lo están haciendo, incluso aunque esto implique un esfuerzo añadido a sus propias tareas y misiones. No podía ser de otra manera ya que, adicionalmente a los contenidos de la Ley Orgánica de la Defensa Nacional antes citados, una de las directrices de la política de defensa, promulgada por el Presidente del Gobierno en la Directiva de Defensa Nacional en vigor es "Conseguir una coordinación eficaz entre los elementos civiles y militares que participan en las acciones en el exterior en operaciones de ayuda humanitaria u operaciones de paz o de gestión de crisis".

\section{LA AYUDA HUMANITARIA Y LAS ORGANIZACIONES INTERNACIONALES}

Las organizaciones internacionales de defensa más importantes, han comprendido, hace ya años, la necesidad de colaborar con sus medios y capacidades que en cada caso estén disponibles. No es lo mismo considerar la estructura de mando y la de fuerza de una alianza como la OTAN, que tener en cuenta las capacidades de la Unión Europea, o pensar en la guía doctrinal que aporta la Organización de las Naciones Unidas.
En el caso de la Alianza Atlántica, se ha creado toda una organización dedicada al planeamiento civil de emergencia, a cuya cabeza se encuentra uno de los comités más importantes de la OTAN, el SCEPC, Senior Civil Emergency Planning Committee, que mantiene un centro de atención permanente, las 24 horas del día, con la finalidad exclusiva de atender a los desastres y emergencias que se produzcan, incluso más allá de las fronteras de los países de la Alianza, y gestionar de la forma más rápida y eficaz la ayuda humanitaria que puedan aportar no sólo los países miembros, sino también los que forman parte del Consejo de Cooperación Euroatlántica. Para ello, la OTAN se ha dotado de la necesaria doctrina de carácter humanitario y de unos comités y grupos de planeamiento, que se ocupan de las diversas áreas a tener en cuenta en los casos de grave catástrofe.

Por su parte, la Unión Europea ha elaborado un "Manual de Coordinación para casos de Emergencias y Crisis", que es consecuencia de un proceso que inició la UE en el año 2004, y que hoy ha dado lugar a una estructura en la que un Centro de Situación, SITCEN, está vigilante, también las 24 horas, a cualquier emergencia o crisis que pueda ocurrir.

Por lo que respecta a las Naciones Unidas, que no dispone de un centro de estas características, ni de unidades militares ni civiles dispuestas para ser alistadas en un plazo de tiempo muy breve, se puede decir que ha elaborado una base teórica de la que se pueden destacar las conocidas como Directrices de Oslo. Estas Directrices fueron redactadas en 1994 en el seno del InterAgency Standing Committee (IASC) de Naciones Unidas, y auspiciadas por la Oficina de Coordinación de los Asuntos Humanitarios de Naciones Unidas (OCHA). Fueron actualizadas en noviembre de 2006. Su objetivo en lo que se refiere al empleo de medios militares y de defensa civil en situaciones de desastres, es establecer un marco para formalizar y mejorar la eficiencia del uso de medios militares y de defensa civil en operaciones internacionales de ayuda humanitaria. Hay que decir, no obstante, que, a diferencia de lo que ocurre con las doctrinas de la OTAN y de la $U E$, plenamente ratificadas por nuestro país, el Gobierno español asume las Directrices de Oslo como marco de referencia en el campo de las acciones humanitarias y que, de acuerdo con ellas, las Fuerzas Armadas son sólo una herramienta complementaria que, al amparo de la Ley 
Orgánica de Defensa Nacional, puede ser utilizada por el Gobierno para hacer frente a catástrofes humanitarias de gran magnitud, por reunir las características adecuadas para convertirse en un instrumento especialmente apto para reaccionar rápida y eficazmente ante este tipo de situaciones.

Existen, igualmente, diversas organizaciones internacionales que, en sus áreas de competencia, tienen previsto algún tipo de intervención en casos de catástrofe. Así podemos citar la Agencia Internacional de la Energía Atómica, INTERPOL, EUROCONTROL, OPAO...

\section{Mirando al futuro}

Decía al comienzo de este trabajo que la coordinación entre Defensa y Ayuda Oficial al Desarrollo debe ir construyéndose poco a poco, con el transcurso del tiempo, que debemos de ir acomodándonos los unos a los otros, y que no es un proceso que se pueda dar por concluido de un día para otro.

Sin lugar a dudas, el proyecto más novedoso en lo que se refiere a esta coordinación es ya hoy una importante realidad y se refiere a las acciones de reconstrucción y desarrollo que están llevando a cabo los Ministerios de Defensa y de Asuntos Exteriores y de Cooperación, centradas en la provincia de Badghis, en Afganistán, donde España lidera el Equipo de Reconstrucción Provincial, PRT, de la aldea de Qala i Naw.
La Agencia Española de Cooperación Internacional para el Desarrollo, AECID, del Ministerio de Asuntos Exteriores y de Cooperación, está desarrollando una intensa y magnífica labor de apoyo a la reconstrucción en la provincia.

Por otra parte, los Ilamados Proyectos de Impacto Rápido, QIP, son realizados y financiados por el componente militar del PRT, como actividades de "cooperación cívico-militar", con el objetivo de aumentar el grado de seguridad de nuestras fuerzas desplegadas y son ejecutados por trabajadores civiles afganos principalmente. Hasta el momento se han terminado más de 60 proyectos de este tipo, entre los que destacan la rehabilitación de la biblioteca pública de esta ciudad, la restauración y ampliación de mezquitas, la construcción de una pista polideportiva, los cursos de informática y de español, la entrega y puesta en funcionamiento de una emisora de FM, el acondicionamiento de un basurero público, la instalación de una planta depuradora de agua y diversos apoyos proporcionados a petición de las autoridades locales.

Éste es, sin duda, el camino a seguir. El camino de una estrecha colaboración entre los dos actores más importantes de la acción exterior del Estado, que se apoyan, colaboran y llevan a lugares muy lejanos la solidaridad de todos los españoles que entienden y desean que parte de los niveles de bienestar de los que gozan sean compartidos con otros países menos favorecidos que necesitan lo más básico porque no lo tienen. $Y$ ahí estaremos juntos, representando a nuestros compatriotas, materializando sus deseos de contribuir a la paz y progreso en el mundo y trasladando su sentimiento de solidaridad y afecto.
NOTAS

Recibido: 24 de enero de 2008 Aceptado: 27 de marzo de 2008
1 Como ejemplo, podemos señalar que de las 60 operaciones de paz que desde 1948 ha puesto en marcha

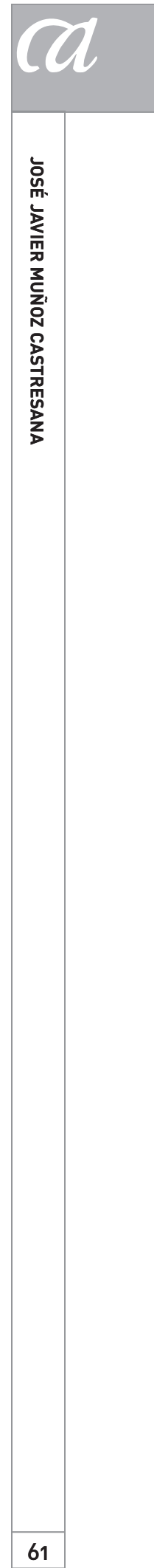

las NN.UU., 13 lo fueron durante la guerra fría y el resto tras la caída del muro de Berlín, de las cuales, 18 están en actividad. 